\title{
Expanding food agency theory and measurement with mixed methods: A study from Philadelphia
}

\author{
Caitlin Bradley Morgan* \\ University of Vermont
}

Submitted September 27, 2019 / Revised December 6, 2019, and March 6 and April 13, 2020 /

Accepted April 13, 2020 / Published online July 10, 2020

Citation: Morgan, C. B. (2020). Expanding food agency theory and measurement with mixed methods: A study from Philadelphia. Journal of Agriculture, Food Systems, and Community Development, 9(4), 229-244. https://doi.org/10.5304/jafscd.2020.094.016

Copyright (C 2020 by the Author. Published by the Lyson Center for Civic Agriculture and Food Systems. Open access under CC-BY license.

\begin{abstract}
This qualitative strand of a mixed-methods study investigates the experiences of a group of lowincome residents of color and university students from Philadelphia, in conjunction with the development of the Cooking and Food Provisioning Scale (CAFPAS). The CAFPAS is a tool for understanding and intervening in people's ability to access and prepare food, an ability known as "food agency." Qualitative data identified in this study reveal aspects of food agency not measured by the scale, such as the constraints of the physical environment and lack of money, or strategic provisioning to overcome barriers to access. Physical distance from food sources combined with income and time barriers makes procuring and preparing food difficult to achieve. Pro-
\end{abstract}

* Caitlin Bradley Morgan, Food Systems Graduate Program and Gund Institute for Environment, University of Vermont, 109 Carrigan Drive, Burlington, VT 05401 USA; and member of the international graduate training program Economics for the Anthropocene; caitlin.b.morgan@uvm.edu visioning practices, such as strategic shopping and gardening, thus emerged as a means to mitigate such socioeconomic barriers to enacting food agency. Personal aspirations - to eat more healthfully, cook more skillfully, and have greater self-sufficiency-also emerged as an unexpectedly important way in which people related to their own food choices and actions. CAFPAS scores are perhaps best understood with accompanying contextual data to elucidate food agency in particular places and life circumstances. Likewise, a qualitative inquiry into food agency can be appropriately contextualized by connecting it to broader patterns in CAFPAS scores. For a full conception of food agency, if it is to be applied in community projects or policy decisions, we need to better understand individuals' preferred actions and the place-based structures that either support or inhibit them.

\section{Funding Disclosure}

This research was funded through a U.S. Department of Agriculture Hatch Grant (VT-H02109). 


\section{Keywords}

Food Agency, Food Systems, Mixed-Methods Research, Food Access

\section{Introduction}

While historically food has been studied in silos, there has been a recent move toward understanding food in the context of systems that are influenced by larger world forces (Francis et al., 2008). A food systems perspective moves across scales, from body to community to society. One such recent attempt at multiscalar, transdisciplinary food research is the development of "food agency" theory. Our research team's conception of food agency aims to understand on-the-ground action: how people employ manual and cognitive skills and sensory perceptions, while navigating and shaping societal structures, to access and prepare food. As an individual, "to have food agency is to be empowered to act throughout the course of planning and preparing meals within a particular food environment" (Trubek, Carabello, Morgan, \& Lahne, 2017, p. 298). Following categorizations from psychology, food agency is a form of personal agency that incorporates social conditions over which people have no direct control (Bandura, 2000, 2004).

Past conceptions of food and behavior have largely excluded external influences on food intake (e.g., Bell \& Marshall, 2003), or recognize food access as part of the equation but still rely on measuring individuals' knowledge, skills, and behaviors (e.g., Vidgen \& Gallegos, 2014). Food agency theory "goes a step further to include this broad array of actions and capacities, and emphasizes the vital role of repeated, skilled actions-assumed and unenunciated by other approaches - in developing those capacities ... [It] advances understanding in regards to such processes as a type of embodied knowledge" (Wolfson et al., 2017 p. 1148). The incorporation of socio-structural systems is one way food agency theory fills the contextual gaps of previous theories. Conceived at the intersection of psychology, anthropology, sociology, and public health scholarship, we argue that this theory allows for a more accurate interpretation of actions, and therefore of consequences, for both the individual and society (Trubek et al., 2017). This kind of transdisciplinary research—connecting theory, cooking behavior, food access, and structural environments - can offer a better understanding of complex problems in socioecological systems, as well as possible solutions (Choi \& Pak, 2006; Knierim \& Callenius, 2018; Wickson, Carew, \& Russell, 2006).

Contemporary food action measurements thus do not account adequately for components of food agency, such as structure and personal skill and self-efficacy. To address this problem, some members of our research team developed the Cooking Action and Food Provisioning Scale (CAFPAS). Based on the food agency framework, this scale conceptualizes cooking behaviors as sociological agency, measuring individuals' ability to set and achieve food provisioning and cooking goals. The three main subcategories - components of the measurement - that emerged in scale development are food self-efficacy (self-perceptions of ability), food attitude (personal attitudes toward food and cooking), and structures (nonfood barriers toward provisioning). The scale has been tested and is structurally valid (Lahne, Wolfson, \& Trubek, 2017). It represents a step forward in measuring the multiple facets that influence how people can source and prepare food.

This tool, designed to take into account a broader set of influences on individual action, was developed in a specific context, as part of a multiyear, multistage, mixed-methods food agency research project. Mixed-methods research is defined by leaders in the field as being diverse in form, involving both qualitative and quantitative "strands" of data, mixed or linked for greater insight than one type alone could provide (Creswell \& Plano Clark, 2007). The first, qualitative phase of this research involved video ethnography and participant observation of home cooks and categories for measuring personal food agency (Carabello, 2015). The second phase involved qualitative data collection through focus groups, from which initial quantitative scale items were developed and underwent an expert review. The third phase involved quantitative testing of a beta version of the scale, administered to a sample. Subsequently, there was statistical validation of the scale to evaluate items and group them thematically (for reference, see Lahne et al., 2017. The scale was developed in a 
classic approach (DeVellis, 2011) through the qualitative research, expert selection of items, large development and validation samples, and refinement to relevant items (Lahne et al., 2017). The first and second phases were pursued in Vermont with mostly white, middle-income participants. Statistical testing was conducted with a national sample of online participants of varied incomes and ethnicities, although not representative of U.S. demographics in terms of lower income, lower education, and other-than-Caucasian respondents. This article is derived from the fourth phase, a qualitative triangulation of the quantitative strand of inquiry, overlapping with the third phase in part of its timeline. Although it was developed with consultation and advising from the wider research team, the phase was designed and executed by this author. The study follows what is called an "explanatory" design in mixed-methods parlance, with qualitative methods following sequentially from quantitative to discern what the qualitative strand can explain about the quantitative strand (Creswell \& Plano Clark, 2007). The explanatory question, in this case, was whether the scale captures meaningful aspects of food agency in different cultural, geographic, and economic contexts.

The objectives of this explanatory study were two-fold. First, to assess the CAFPAS through qualitative means to complement quantitative statistical tests. The study was designed to illuminate the CAFPAS's efficacy by capturing the complexity of early qualitative research in a different setting. This expanded qualitative data is important information as people begin to use the scale to evaluate food agency. I asked, what experiences are or are not captured from a universalizing tool developed in particular circumstances? The second objective was to extend these qualitative insights into the still-developing theory of food agency. To achieve these objectives, I conducted research in Philadelphia, with participants whose life circumstances were different from those who participated in earlier phases of research. Philadelphian participants lived in an urban environment, were a mix of university students and community members from a low-income section of the city, and were majority people of color. Because the race, income, and urban life of the participant group were distinct from Vermont participants, I hypothesized that, while established components of food agency might be the same, the supports and barriers of agency would manifest differently than those revealed in earlier qualitative work and incorporated in scale development.

\section{Literature Review}

From the literature, it would seem that low-income U.S. residents of color likely face the greatest structural barriers to food agency. Diet-related illnesses plague marginalized groups at higher rates than the general population; Black and Mexican American adults, for example, are much more likely to be obese than white adults (Ogden, Lamb, Carrol, \& Flegal, 2010). Although there are racial distinctions, poor are more likely to be obese than richer people (Zhang \& Wang, 2004). And while low-income Americans cook more than their wealthier counterparts (Trubek, 2017), they still suffer disproportionate health disparities from systematic differences like socioeconomic status (Braveman et al., 2011). Accessing healthy and affordable food is a widespread problem, most prominently in lowincome neighborhoods of color (Bell, Mora, Hagan, Rubin, Karpyn, 2013). These social determinants of health show that people's food lives manifest differently across demographic divides.

The intersection of structural and individual supports and barriers is where agency takes place. What happens in the kitchen is always in flux and contingent on external realities (Sutton, 2014). Personal context - the environments in which one's life plays out-are shifting structures, with shifting influences over agency (Sobal \& Bisogni, 2009). This study looks specifically at those social and environmental influences on personal experience, asking: what supports agency here? What inhibits it? What is emergent and unforeseen? Are these things captured in the scale and in our general theorizing?

To capture these questions in a relevant context, this research took place in Philadelphia. Philadelphia is a post-industrial city that saw population decline during the second half of the last century, as well as declining property values, jobs, education, and community resources. Many of its lowincome neighborhoods experience substantial food 
insecurity (Meenar \& Hoover, 2012). Philadelphia's foodshed is a complex mix of hyper-urban and rural-adjacent, as it is within 100 miles of other major metropolitan areas, and also within reach of agricultural counties (Kremer \& Schreuder, 2012). The city has a constant supply of fresh produce, much of it imported through the Port of Philadelphia, and in some parts of the city, low-income neighborhoods gain access to produce from curbside street vendors (Brinkley, Chrisinger, \& Hillier, 2013). The city has majority Black residents, and Black Philadelphians experience more diet-related disease and less healthy food access than other city residents (Mui, Khojasteh, Hodgson, \& Raja, 2018). Food access in Philadelphia depends on multiple factors that include food quality, variety, availability, and affordability, as well as cultural preferences (Meenar, 2017).

As Lahne et al. (2017) acknowledge about the CAFPAS, it "explicitly does not include actual items that might represent social structure, such as income, sex, education level, and so on...the structure [sub]scale is meant to measure an individual's perception of structure, not to measure structure 'objectively'. There are a huge variety of possible structural effects” (p. 97). This study describes those structural effects in a specific location and population through integrating multiple methods. Mixed methods research has been argued as especially relevant for studies of local food consumption, barriers to food access, and how food security connects to food culture (Mares, 2017). Although they employ a different methodology, Meenar (2017) has also used mixed methods to illuminate a "multidimensional socioeconomic problem tied to the built environment" (p. 1181). In this case, Meenar (2017) focuses on food insecurity and vulnerability in Philadelphia, and argues that mixedmethod approaches provide more comprehensive assessment of food environments. In the current study, qualitative methods reveal circumstances that supported or inhibited participants from accessing and preparing food, circumstances not apparent from responses offered by the scale.

\section{Methods}

This study is the fourth phase of an ongoing, mixed-methods, multiphase study, concurrent with the development and validation of a quantitative measure that began before this work and continued after it. I designed the research to be an in-depth qualitative exploratory study of theoretical and quantitative concepts to inform that ongoing project. A respondent's setting is often overlooked in measurements and assessments (González-Calvo, González, \& Lorig, 1997), which is precisely what food agency scholarship tries to avoid. One of the ways to prevent an assumption of cultural universality and achieve a high quality "translation" of reality into measurement is pilot testing with a small sample of participants from targeted cultural or social classes (González-Calvo et al., 1997). Initial qualitative research had taken place in Vermont, a rural and overwhelmingly white state (U.S. Census Bureau, n.d.). In the scale development sample, highly educated, male, and Caucasian participants were overrepresented; in the validation sample, quotas were set to ensure more female respondents and a diversity of education and racial and ethnic backgrounds (Lahne et al. 2017).

This stage of the study took place at a healthy cooking techniques class in Philadelphia, Pennsylvania, an integrated college and community course offered to Drexel University students and residents of the Mantua neighborhood. Mantua is one of five "Promise Zones" designated by the Obama administration, which are identified by need and potential for fast-tracking of federal grants. Median household income in the area is under US $\$ 17,000$ and unemployment is 20 percent, double that of Philadelphia as a whole. More than half of Mantua residents live below the poverty line, and 90 percent are African American (Kilpatrick, 2014). As a study site, this is quite a contrast to Chittenden County, Vermont, which has fewer than 170,000 residents and is surrounded by an agricultural state. The county's median household income is nearly US $\$ 67,000$ and unemployment is only 11 percent. Residents are 90 percent Caucasian (U.S. Census Bureau, n.d.); the Vermont-based research phases included a similar ratio of white participants.

Recruiting from a cooking class allowed me to reach people who were interested in food preparation and who were actively engaged in their own food agency. The sampling strategy was to recruit as many people as possible from the healthy cook- 
ing class in order to capture the widest range of responses. Recruitment ${ }^{1}$ took place on the first week of the ten-week course. The function of this purposeful sample (Marshall, 1996) was to obtain similar qualitative data to what had informed development of the CAFPAS. I sought in-depth information from a similarly sized group of people who were also interested in food and cooking but occupying different life circumstances from focus groups in Vermont. The purpose of this was to mimic the kind of data from which the original scale items (i.e., questions) were derived. Everyone enrolled in the cooking course demonstrated interest in participating; almost all (eight community residents and five students; 13 out of 15 total students) were interviewed at the beginning of the course. Follow-up interviews and one focus group took place three months after the course ended, for longitudinal data about lasting impressions and effects. (The focus group took the place of followup interviews for college students, due to scheduling constraints.) The study retained seven of eight community residents and three of five students in follow-up. Participants received a US $\$ 20$ gift card after the first interview and an additional US $\$ 50$ card upon completion of the follow-up. Interview and focus group protocols were developed using themes from the scale-what supports cooking, what inhibits cooking, what are someone's actual cooking practices - to create a semistructured format that allowed for both direct responses and unexpected information. All interviews took place at a community center near Mantua or on Drexel campus and were audio recorded and transcribed, with permission and approval of participants and my university's Institutional Review Board.

Analysis of the data was a combination of grounded theory and thematically informed coding (Dowding, 2013), which was based on literature review of concepts related to food agency. Adapting grounded theory by using "sensitizing concepts" permitted the literature to act as a starting point for analysis while also allowing for unexpected themes to emerge (Bowen, G. A., 2006). First, I conducted a literature review to explore the existing research on constructs from the food agency scale and on the specific research population. This included literature on the connection between health, nutrition, and cooking; barriers to individual cooking practices; cooking skill and selfefficacy; food and cooking education and literacy; and social determinants of health. (For the full literature review, see Morgan, 2016.) I then developed a qualitative codebook based on a deep reading of four of the first-round interviews (with two college students and two community residents). I developed modified codebooks for follow-up interviews (which had a different question guide), based on the original codebook and a deep reading of two of the follow-up interviews. This resulted in an extensive list of codes. I shortened the list to emergent groupings of codes, or themes. From the coded material, I developed items related to food agency — again, based on our conception, on the literature review, and on the extant scale. To integrate the interview data with the scale, I reviewed major qualitative themes, broke them down into more specific component parts, and then compared them to current scale items in order to determine whether those themes are reflected in the scale.

These two sets of items-mine and the scale's - were arrayed side-by-side for clearer visual understanding of the connection between the two (see Table 1). One way of merging qualitative and quantitative strands of research is a joint display: a figure or table in which the two sources of data can be directly compared. This visual side-by-side comparison highlights convergent and divergent places in the two strands (Creswell \& Plano Clark, 2007). Although this table is not a "quantification of qualitative data," it does depend on presenting the qualitative data to be comparable to the results of past quantitative analysis i.e., the scale items.

This array is critical because it allows connections to emerge that might remain hidden in other forms of analysis, and it provides a direct reflection on existing quantitative data collection. While traditional mixed-methods scholars often look for confirmatory findings (Creswell \& Plano Clark, 2007),

\footnotetext{
${ }^{1}$ Recruitment in the Vermont study was a convenience sample, recruited through flyers posted on the university campus and surrounding community as well as on email listservs, to find willing participants for exploratory research.
} 
conflicting findings are equally useful here for emergent understandings of complicated social phenomena (Wagner et al., 2012). Here, it illuminated both similarities and discrepancies between qualitative data from Philadelphians and the scale's items.

\section{Results}

The primary result of this work is a side-by-side array of the quantitative measure (the result of qualitative and quantitative development) with the most recent qualitative data and emergent themes (see Table 1). Rather than following a typical

\section{Table 1. Items from the CAFPAS Arrayed with Related Qualitative Data and Themes}

\begin{tabular}{|c|c|c|}
\hline CAFPAS Item & Related Experiences in Qualitative Data & Qualitative Theme \\
\hline $\begin{array}{l}\text { Before I start cooking, I usually have a mental } \\
\text { plan of all the steps I will need to complete. }\end{array}$ & $\begin{array}{l}\text { a. Inability to plan ahead } \\
\text { b. Time management }\end{array}$ & $\begin{array}{l}\text { a. Constraint (Skill) } \\
\text { b. Strategy (Cooking) }\end{array}$ \\
\hline $\begin{array}{l}\text { In preparing food, I can solve most problems } \\
\text { with enough effort. }\end{array}$ & -- & -- \\
\hline $\begin{array}{l}\text { When I shop for food, I know how I will use the } \\
\text { ingredients I am purchasing. }\end{array}$ & $\begin{array}{l}\text { a. Lack of access to desired } \\
\text { education in nutrition or cooking } \\
\text { b. Inability to plan ahead }\end{array}$ & $\begin{array}{l}\text { a. Constraint (Income) } \\
\text { b. Constraint (Skill) }\end{array}$ \\
\hline I feel like cooking is a waste of effort. & -- & -- \\
\hline $\begin{array}{l}\text { My family responsibilities prevent me from } \\
\text { having time to prepare meals. }\end{array}$ & -- & -- \\
\hline I feel limited by my lack of cooking knowledge. & $\begin{array}{l}\text { a. Lack of access to desired } \\
\text { education in nutrition or cooking } \\
\text { b. Building technique }\end{array}$ & $\begin{array}{l}\text { a. Constraint (Income) } \\
\text { b. Aspiration (Cooking proficiency) }\end{array}$ \\
\hline $\begin{array}{l}\text { If everything else is equal, I choose to cook } \\
\text { rather than have food prepared by someone } \\
\text { else. }\end{array}$ & $\begin{array}{l}\text { a. Distance from family who would } \\
\text { prepare meals } \\
\text { b. Inability to purchase prepared food } \\
\text { when desired }\end{array}$ & $\begin{array}{l}\text { a. Constraint (Environment) } \\
\text { b. Constraint (Income) }\end{array}$ \\
\hline I find cooking a very fulfilling activity. & -- & -- \\
\hline $\begin{array}{l}\text { Compared to other activities, cooking brings me } \\
\text { little enjoyment. }\end{array}$ & -- & -- \\
\hline $\begin{array}{l}\text { I am confident creating meals from the } \\
\text { ingredients I have on hand. }\end{array}$ & -- & -- \\
\hline $\begin{array}{l}\text { I am inspired to cook for other people, like my } \\
\text { family or friends. }\end{array}$ & Accounting for others' tastes & Strategy (Cooking) \\
\hline I think a lot about what I will cook or eat. & - & -- \\
\hline $\begin{array}{l}\text { I know where to find the ingredients I need to } \\
\text { prepare a meal. }\end{array}$ & Inability to plan ahead & Constraint (Skill) \\
\hline $\begin{array}{l}\text { For me, cooking is just something to get through } \\
\text { as quickly as possible. }\end{array}$ & -- & -- \\
\hline $\begin{array}{l}\text { I feel burdened by having to cook for other } \\
\text { people, like my family or friends. }\end{array}$ & Accounting for others' tastes & Strategy (Cooking) \\
\hline I know how to use the kitchen equipment I have. & Inexperience with proper technique & Constraint (Skill) \\
\hline $\begin{array}{l}\text { When preparing food, it is easy for me to } \\
\text { accomplish my desired results. }\end{array}$ & Ability to cook what one envisions & Aspiration (Cooking Proficiency) \\
\hline I am comfortable preparing food. & -- & -- \\
\hline $\begin{array}{l}\text { My job responsibilities prevent me from having } \\
\text { the time to prepare meals. }\end{array}$ & Distance between home and work & Constraint (Environment) \\
\hline $\begin{array}{l}\text { When preparing food, I am confident that I can } \\
\text { deal with unexpected results. }\end{array}$ & Ability to cook what one envisions & Aspiration (Cooking Proficiency) \\
\hline I wish that I had more time to plan meals. & $\begin{array}{l}\text { a. Limited time } \\
\text { b. Efficiency in cooking }\end{array}$ & $\begin{array}{l}\text { a. Constraint (Time) } \\
\text { b. Aspiration (Cooking Proficiency) }\end{array}$ \\
\hline
\end{tabular}

Table 1 continues 
Table 1 continued

\begin{tabular}{lll}
\hline CAFPAS Item & Related Experiences in Qualitative Data & Qualitative Theme \\
\hline I am involved in daily meal preparation. & - & - \\
If I try making a new type of food and it does not & -- & - \\
come out right, I usually do not try to make it & \\
again. \\
When presented with two similar products to pur- & -- \\
chase, I feel confident choosing between them. & -- \\
My social responsibilities prevent me from having & -- & - \\
the time to prepare meals. \\
I prefer to spend my time on more important \\
things than food.
\end{tabular}

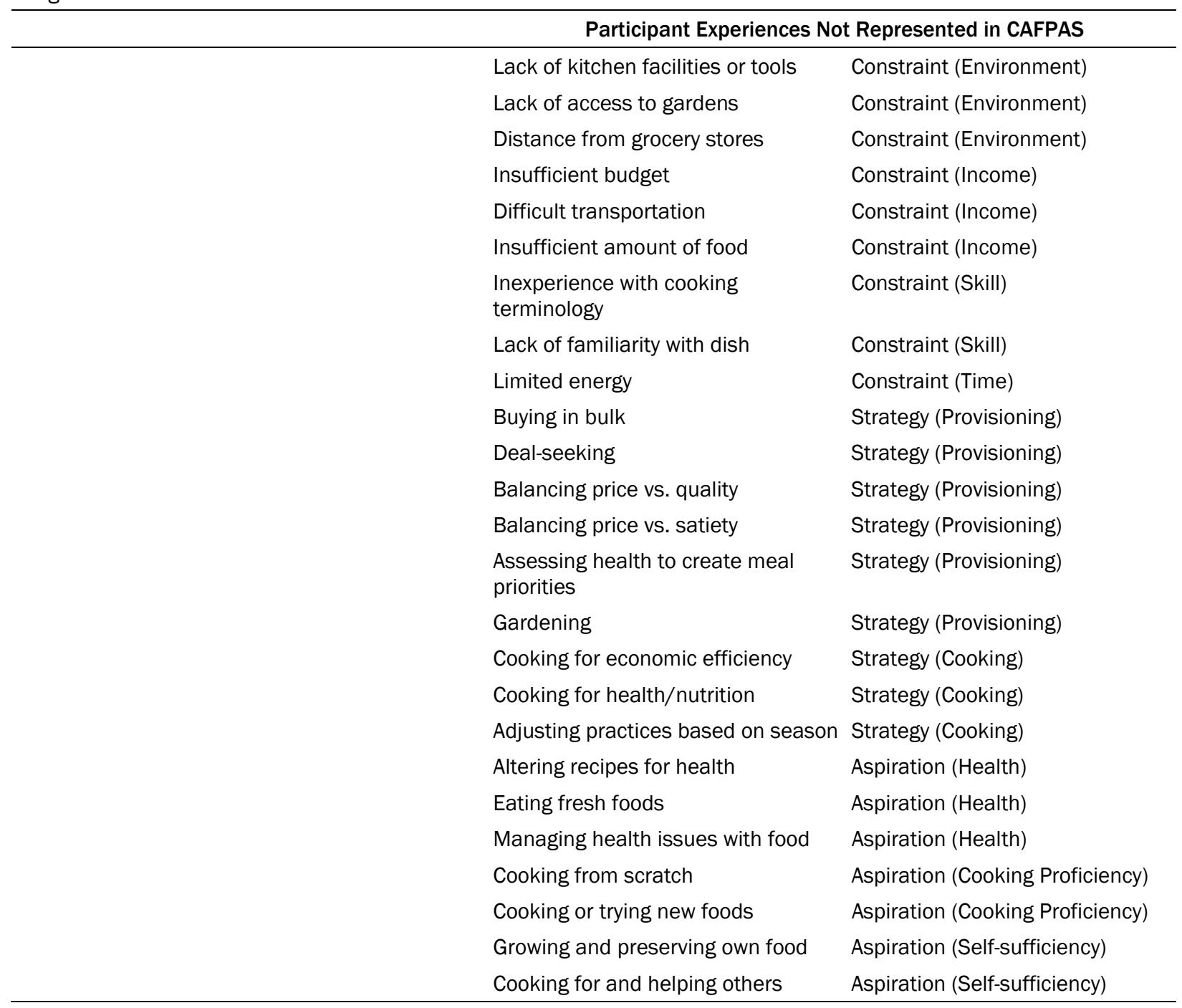

descriptive qualitative analysis, this method supports the study's objectives of comparing qualitative data directly with the quantitative measure. It provides systematic insights into additional facets of food agency in a similar form as the scale and is equally succinct. The table visually demonstrates the themes of participants' experience of food agency that are reflected in the scale and the ones 
that are not. Qualitative themes fall into three main groups: constraints on agency, strategies for provisioning and preparation of food, and aspirations related to food-the latter emerging from grounded theory coding. ${ }^{2}$ Each theme is illustrated by specific examples from the qualitative data, which are compared to specific items from the scale. Experiences and themes from the qualitative data that are not related to any CAFPAS items are listed at the bottom of the table. One experience or theme may be reflected by multiple CAFPAS items. For an example of the scaffolding behind each, see Appendix or Morgan (2016). Where there is a "--" in the table, no Philadelphia participants indicated the item as part of their food actions.

The array shown in Table 1 is a top-level summation of more specific and complex data. For example, four primary constraints on agency emerged: physical environment, lack of time or energy to shop or cook, lack of money, and lack of cooking skill. Each of these arose from multiple pieces of specific data. This table demonstrates which of the group's experiences would not be captured by filling out the CAFPAS. It confirms aspects of food agency in the scale as well as gaps in the scale's ability to capture this group's actions, shedding light on additional aspects of food agency that were not previously documented.

The table reveals some overlap in CAFPAS food agency measurement and facets of participants' lived experiences. However, it also reveals many constraints and supports of agency that are not represented by any scale items. The biggest gaps in CAFPAS measurement of these qualitative themes are environmental barriers, income barriers, and provisioning strategies that support agency in overcoming barriers.

\section{Constraints}

The primary constraints on agency that emerged for this group were physical environment, lack of time or energy to shop or cook, lack of money, and lack of cooking skill. It is worth noting that these constraints have significant overlap. For example, many people struggled with time-efficient procure- ment of groceries. Transportation is a struggle-an issue not only of physical environment in distance from stores, but also of time, with bus trips sometimes adding hours to the task of shopping. It can also be seen as an issue of income, since for many participants, not being able to afford a car (or taxi) limits how much they can buy per shopping trip and how frequently they must go to the store. As one participant, Annie, described, "I'm so exhausted at the end of the day ... just the fact of getting there is time consuming. When I'm in the supermarket itself . . I'm in there 15 minutes, I'm done, but just getting there, it takes more than an hour because I take public transportation.” Here, environment, time, and money all converge to make it difficult for Annie to access groceries, despite the fact that she has plenty of cooking skill in the kitchen.

The scale has few items that relate to these barriers. The only item connected to the effects of physical place is "I rely on someone else to prepare the majority of my meals." This loosely links to the issue of distance to family that some participants, notably college students, cited as an issue in their lives, although if students did rely on parents, but could not get to them, there is no clear way to indicate this in the survey. The items relating to income ask whether a respondent prefers to cook their own food or purchase it; this framing does not allow for someone to prefer to buy prepared food but not be able to afford it. The scale does ask about skill and confidence in the kitchen, albeit in ways that do not exactly match the specific areas in which participants identify their deficits, such as not understanding terminology in cookbooks, or not knowing the proper techniques demanded by recipes. Time constraints, by contrast, are well represented in the scale. Nearly all participants mentioned time as a barrier to their cooking; interestingly, they were just as likely to frame time deficit as a lack of energy. That nuance is not represented in the scale. It may be important because people who are more skilled might need less energy to complete tasks.

\footnotetext{
2 These categories are different than the scale subsections in order to replicate early qualitative research on the constraints and supports of food agency. By contrast, the scale's subsections were developed from computational testing.
} 


\section{Supports}

In terms of what supports food agency (one of this study's original questions), interviews clearly revealed that participants are very strategic about how they plan and provision around food. Their strategies allow them some freedom within economically or environmentally constrained circumstances. Most plans revolve around shopping for different types of foods at different stores in order to maximize quality or convenience while minimizing cost. Two participants named their provisioning habits as the reason they eat the way they want to, despite limited incomes. They verbally rated themselves as 10 out of 10 , with totally free and unconstrained food agency. One uses coupons, buys in bulk, and seeks the lowest prices; the other grows the majority of her vegetables in a community garden plot, drastically lowering her grocery budget. Their agency arises from careful, active engagement with their best food-sourcing tactics.

Procurement strategies do not appear in the scale as a support of food agency. There is one associated question, "When I shop for food, I know how I will use the ingredients I am purchasing." An item that might more accurately reflect how Philadelphia participants bolster their agency might instead be something like "My strategies for obtaining food allow me to have what I need to cook." Such an item would allow for more flexibility around how people can procure food, beyond just purchasing. Cooking strategies are much more represented in the scale, from time management, to social relationships in cooking, to planning based on ingredient availability. But if people cannot get food, it may not matter whether they have the skills and inclination to cook it.

\section{Aspiration: An emergent aspect}

Aspiration-to eat more healthfully, cook more skillfully, and have greater self-sufficiencyemerged as a consistent theme when participants spoke of their food experiences. They hoped, through their own efforts, to attain a greater level of agency. This is not surprising in a group of people who self-selected into a course on healthy cooking techniques, but I did not predict the variety nor force of participants' food ambitions. As a facet of food agency, aspiration emerged an unex- pectedly important way in which people related to their own food choices and actions.

Participant aspirations for healthy eating are not reflected in the food agency scale precisely because it was designed to be nonprescriptive regarding personal diets. And yet, health and cooking are two things that Philadelphian participants often conflated. Cooking from scratch, yet another aspiration, is likewise not present in the scale, as it is difficult to define and, again, potentially prescriptive. Cooking technique and planning appear in the scale, whereas trying new food and understanding cooking jargon do not. While aspiration for greater skill could easily fit into the CAFPAS category of "food attitudes," it is not represented in the scale. Where cooking-related goals are represented, they appear in present terms, not aspirational ones; there is no way for respondents to note discrepancy between their current abilities and what they wish to achieve in the future. The implications of this are discussed below.

\section{Discussion}

... while price is paramount, low-income people are neither unthinking dupes of the corporate food system motivated only by appetite, nor overly rational calculators driven only by price, but inhabitants of marginalized yet complex social worlds in which they must actively navigate a variety of barriers to obtain the foods they prefer. (Alkon et al., 2013)

This discussion blends insights into both the CAFPAS and food agency theory more broadly. Nearly all the constraints on food agency emergent in the qualitative data can be connected to issues of socioeconomic status. Constraints such as lack of appropriate cooking facilities and tools, or distance from grocery stores and difficulties with transportation, could be alleviated with greater access to resources. This finding confirms some existing literature about urban food access: what is important for this study is the particulars of how participants skillfully navigate around these barriers, that is, how they enact food agency. Provisioning strategies appear as means to mitigate socioeconomic struggles. Interestingly, many of the strategies are 
like ones recounted by more financially comfortable participants in Vermont. Strategies like shopping at different stores for the best deals on different foodstuffs, or growing vegetables to reduce food budgets are tools for making money go as far as possible in accessing quality food. Perhaps unsurprisingly in a group of low-income participants, lack of money strongly influences needs and actions regarding food and resulting experiences of food agency. The skills used to navigate personal circumstance matter to the individuals in this study, but they also matter broadly in supporting health and wellbeing. The personal ability to organize, plan, shop, and cook increases chances of healthy cooking (Bisogni, Jastran, Seligson, \& Thompson, 2012).

Although structure appears to be this group's main stumbling block to shopping and cooking, it is only a small part of the CAFPAS, representing five of 28 total items. Ability to plan and complete a cooking project are well represented by scale items, but for these participants, cooking abilities are secondary to whether they can get the ingredients they want to cook in the first place. The primary ways in which many of them enact agency is through sourcing food, despite structural impediments to doing so. Their stories echo studies done with urban residents of color, which show that low-income shoppers in food deserts do not necessarily buy groceries at the oft-referenced gas stations, but instead travel outside their own neighborhoods to get food (Rose, 2011). The cost of that travel, rather than knowledge or distance, is the primary barrier to food access (Alkon et al., 2013) and to cooking (Wolfson, Bleich, Smith, \& Frattaroli, 2016). Several national nutritional programs focus on building shopping skills, such as Cooking Matters or the YMCA diabetes prevention program. These programs are designed to support personal capacity and bring recognition to the importance of personal environment. It may be worthwhile for more cooking courses to incorporate provisioning strategies and skills.

It is important to note that none of the participants have children still at home-likely part of the reason they could participate in the cooking course, this research, and perhaps also in time-intensive procurement strategies. While possibly a weakness of this sample, it opens the door for deeper comparison to research with parents. In their consideration of working mothers, Bowen and her colleagues point out that the societal pressure to cook remains, even as time available for cooking has decreased (S. Bowen, Elliot, \& Brenton, 2014). Being poor, the authors contend, "makes it nearly impossible to enact the foodie version of a homecooked meal" (p. 23). Although this study did not reveal many experiences related to social pressures around cooking, a study with parents of small children would probably reflect many more of such CAFPAS items. Further study could explore supporting food agency through different methods and under different circumstances such as parenthood.

The CAFPAS items that do cover food provisioning and preparation do not reflect how able someone is to purchase the ingredients they desire, whether because of physical access, financial ability, or effective deal-seeking. For example, one might always be able "to decide what I would like to eat at any given time," or "feel confident choosing between" two similar products, but not be able to access the ingredients to prepare what they would like to eat, or have the money to buy either of two similar products. Although the CAFPAS has several items describing feelings, including (lack of) enjoyment of cooking, these feelings did not emerge as important factors for many participants in this study. People prepared food as needed; although their skill and self-efficacy had an impact, through familiarity with technique or equipment, their own feelings seemed less relevant to whether they cooked. The exception was for feelings of low energy. This disconnect between scale items and people's reported motivations may suggest that, for people of limited means, enacting food agency is a requirement, not a luxury of choice over whether or not to cook.

For these participants, aspiration is not superseded by low socioeconomic status. Despite constraints, participants aspire to healthier choices and options, more effective action, and greater selfsufficiency. During interviews, they sometimes mined me for information: did I know how to can food? Are raw vegetables healthier than cooked ones? I heard more references to gardening for 
food access than I did to services like food banks or SNAP benefits. Some cooking-related aspirations appear in the CAFPAS, although they (perhaps appropriately) are framed in present terms, not forward-thinking ones. The scale is not intended to measure the discrepancy between where people are and where they wish to be, but those insights could shed light on the ways in which low-income and structurally-constrained populations can best be supported in increasing food agency. While aspiration might not make a difference in someone's agency in this moment, I suspect it affects how agency develops. If the scale is to be used in pre- and post-testing of classes or other events, it might also be useful to track whether changes in agency are related to personal aspiration.

These various ways of understanding cooking and food provisioning have serious implications for policy and health initiatives. As Wolfson and others (2017) note, when the "assumptions about cooking skills are not grounded in theory, they unintentionally shape the development and evaluation of interventions designed with the intent to shift or enhance the practices of participants" ( $p$. 1148). If we assume that the problem is that people do not know how to cook, but the real problem is that they don't have a car with which to buy groceries, then interventions relying on cooking education and home economics will not solve the problem. If we know that people would rather have access to a garden than a food bank, another food bank may not be the best service. This group, for the most part, wants to be supported by building personal capacity. They see opportunity for increasing agency by changing their own skill level, not changing the larger forces. This target makes sense; it is what they can control. But from a systems perspective, to increase agency for many, it also makes sense to work on structures. For these participants, structural supports of food agency might be making higher quality food more easily accessible in urban neighborhoods. Data from other parts of our study (see Morgan, 2016) suggest that having transparent information about food's origins, cooking education for whoever wants it, and gardening education and community garden plots would further support the individual food agency of this group. For a full conception of food agency, if it is to be applied in community projects or policy decisions, we need to understand individuals' preferred actions and the structures that either support or inhibit them, ideally working directly with community members to develop place-based plans.

Based on their descriptions of their daily food actions and attitudes, I suspect that some participants would have relatively high food agency scores, in part because they are so constrained by circumstances. ${ }^{3}$ Many of them reported complex, time- and skill-intensive cooking and provisioning strategies that they acquired to negotiate between their limited means and high standards of health and nutrition. Interim statistical testing of the CAFPAS samples show that income and food agency scores generally are unpredictably related. The average score is steady across nearly all income groups, dipping slightly for people making US $\$ 125,000$ to US $\$ 150,000$ a year. Overall, food agency scores are lowest at the lowest and highest ends of the income spectrum (Lahne, 2016). This insight raises some questions about food agency theory broadly. Is someone a stronger agent because they are not only able, but required, to prepare their own food? Would food agency decrease if a capable but unwilling cook suddenly had more access to money and therefore greater ability to buy themselves out of food preparation? It seems possible that more structural constraints on agency actually result in greater self-efficacy and skill as people navigate barriers successfully. To possess food agency, one might need either ability or money; maybe it is best to have a good measure of both. Having very little money might impede agency even when skill and self-efficacy exist, whereas having a lot of money might impede the development of skill and self-efficacy to build agency beyond financial ability to pay.

While urban environment and socioeconomic themes show up consistently in this data, racial themes remain relatively obscured, except in a few instances. One participant directly linked her ethnic

\footnotetext{
${ }^{3}$ Participants were not able to complete the CAFPAS because its items were still being tested for explanatory power.
} 
and racial identity to her food choices, citing the inherent wisdom of poor and enslaved Black Americans' culinary choices: the healthfulness of what can be dug out of the dirt (i.e., vegetables) and the preservative power of fried meats. Another mentioned needing to choose foods based on low sodium and seemed to link this to hypertension risks for Black Americans. One woman made food choices based on her Filipina heritage and upbringing, cooking mostly Asian foods and eschewing mainstream American foods (like donuts for breakfast) that she saw as inherently poor in nutrition and quality. These and other experiences point to the kinds of foods around which participants organized their food actions, but they did not appear to influence the success or failure of those actions, with the exception of the Filipina participant struggling to source some Asian ingredients. Race may be more of an issue of food identity than food agency. Initial tests on the relationship on food agency scores and income were not available for food agency and race, as the development and validation samples did not have enough respondents of color for statistical significance. Future testing could illuminate more about this relationship and whether the scale is equally predictive across racial categories.

Food justice movements, socioeconomic structures, and personal agency all interact in placebased ways. One participant is able to enact a much higher level of food agency due to recent access to a community garden plot, something that was unavailable to her upon first emigrating to the U.S., which had negatively impacted her family's access to culturally appropriate foods. Her current food sourcing practices are a mixture of personal skill, cultural identity, and community resources. As mentioned earlier, her provisioning methods allow her a feeling of unconstrained agency, despite having a very limited income. As theorized previously, food agency is dependent on skill, self-efficacy, and structure alike; and it can shift substantially if one of these factors changes.

\section{Conclusion}

Without data from this community in Philadelphia, we could fail to notice the importance of food provisioning strategies, both as a stumbling block, and as an area for negotiating personal food agency within constraints. This study was able to unpack the importance of strategic skill and aspiration in food agency development. While this personal ability and growth were important, they are not currently probed in the CAFPAS.

As a theory, food agency intends to bridge the gap between pure sociological conceptions and the more individualistic perspective of traditional nutrition study. It brings together the twin truths that people's circumstances strongly influence their lives, and they make choices of their own volition. Ideally, food agency theory will contribute to the conversation about how community and university actors can work together toward productive action research rooted in place (Porter, Woodsum, \& Hargraves, 2018). Organizations focused on incremental change-as granting agencies often aremay require academics and community workers to use quantitative tools to measure progress. But if the tools themselves are flawed, perhaps because they do not fully reflect the structural influences that both the literature and this data show to be important, then the measurement of progress can become tautological. I hope this paper serves as an example of methods for developing meaningful and more democratic measurements of holistic processes, and the kinds of experiences that can remain invisible to academic inquiry unless they are intentionally sought out.

Luyt (2012) argues that the development, validation, and revision of a measurement tool is "a cyclical process best undertaken through mixed methods research, emphasizing the complementarity of qualitative and quantitative methods" and placing equal emphasis on consistent and inconsistent findings (pp. 295-296). The variety and specificity of insights about food agency that emerged from this project suggest that CAFPAS scores are perhaps best understood with accompanying, circumstantial data. Likewise, qualitative inquiry into food agency can be appropriately contextualized by connecting it to broader patterns in CAFPAS data. This study reveals aspects of food agency that deserve deeper consideration, such as provisioning strategies, and the possibility that constraints on agency might, counterintuitively, result in increased personal agency through 
the acquisition of necessary skills. This work also directly counters mainstream stereotypes of lowincome, urban eaters. Participants here aspire to better eating and cooking, and employ diverse, intentional strategies to acquire high-quality foods, against the odds.

\section{Acknowledgments}

I gratefully thank Amy Trubek and Jacob Lahne for inclusion in their research, and their help in the creation, ongoing support, and completion of this project. Maria Carabello assisted in data collection and gave much-needed advice. James Fuestel at
Drexel University kindly opened his classroom to this research, and Drexel University's Dornsife Center for Neighborhood Partnerships was critically helpful in recruiting participants. Julia Wolfson provided helpful comments on the original manuscript. Teresa Mares and Bernice Garnett offered invaluable guidance and feedback on the thesis from which this article was developed. This article was much improved thanks to the comments from two anonymous reviewers. My deep gratitude to the participants who made this project possible.

\section{References}

Alkon, A. H., Block, D., Moore, K., Gillis, C., DiNuccio, N., \& Chavez, N. (2013). Foodways of the urban poor. Geoforum, 48, 126-135. https://doi.org/10.1016/j.geoforum.2013.04.021

Bandura, A. (2000). Exercise of human agency through collective efficacy. Current Directions in Psychological Science, 9(3), 75-78. https://doi.org/10.1111/1467-8721.00064

Bandura, A. (2004). Health promotion by social cognitive means. Health Education \& Behavior, 31(2), 143-164. https://doi.org/10.1177/1090198104263660

Bell, J., Mora, G., Hagan, E., Rubin, V., Karpyn, A. (2013). Access to healthy food and why it matters: A review of the research. Retrieved from http://thefoodtrust.org/uploads/media items/access-to-healthy-food.original.pdf

Bell, R., \& Marshall, D. W. (2003). The construct of food involvement in behavioral research: Scale development and validation. Appetite, 40(3), 235-244. https://doi.org/10.1016/S0195-6663(03)00009-6

Bisogni, C. A., Jastran, M., Seligson, M., \& Thompson, A. (2012). How people interpret healthy eating: Contributions of qualitative research. Journal of Nutrition Education and Behavior, 44(4), 282-301. https://doi.org/10.1016/i.jneb.2011.11.009

Bowen, G. A. (2006). Grounded theory and sensitizing concept. International Journal of Qualitative Methods, 5(3), 12-23. https://doi.org/10.1177/160940690600500304

Bowen, S., Elliott, S., \& Brenton, J. (2014). The joy of cooking? Contexts, 13(3), 20-25. https://doi.org/10.1177/1536504214545755

Braveman, P. A., Kumanyika, S., Fielding, J., LaVeist, T., Borrell, L. N., Manderscheid, R., \& Troutman, A. (2011). Health disparities and health equity: The issue is justice. American Journal of Public Health, 101(S1), S149-S155. https://doi.org/10.2105/AJPH.2010.300062

Brinkley, C., Chrisinger, B., \& Hillier, A. (2013). Tradition of healthy food access in low-income neighborhoods: Price and variety of curbside produce vending compared to conventional retailers. Journal of Agriculture, Food Systems, and Community Development, 4(1), 155-169. https://doi.org/10.5304/jafscd.2013.041.011

Carabello, M. (2015). Defining food agency: An ethnographic exploration of home and student cooks in the Northeast. UVM Graduate College Dissertations and Theses, No. 453. https://scholarworks.uvm.edu/graddis/453

Choi, B. C. K., \& Pak, A. W. P. (2006). Multidisciplinarity, interdisciplinarity and transdisciplinarity in health research, services, education and policy: 1. Definitions, objectives, and evidence of effectiveness. Clinical and Investigative Medicine, 29(6), 351-364. Retrieved from https://pubmed.ncbi.nlm.nih.gov/17330451/

Creswell, J. W., \& Plano Clark, V. L. (2007). Designing and conducting mixed methods research. Thousand Oaks, CA: SAGE.

DeVellis, R. F. (2011). Scale development: Theory and applications ( $3^{\text {rd }}$ ed.). Thousand Oaks, CA: SAGE.

Dowding, D. (2013). Best practices for mixed methods research in the health sciences, John W. Creswell, Ann Carroll Klassen, Vicki L. Plano Clark, Katherine Clegg Smith for the Office of Behavioral and Social Sciences Research; Qualitative methods overview, Jo Moriarty [Book review]. Qualitative Social Work, 12(4), 541-545. https://doi.org/10.1177/1473325013493540a 
Francis, C. A., Lieblein, G., Breland, T. A., Salomonsson, L., Geber, U., Sriskandarajah, N., \& Langer, V. (2008). Transdisciplinary research for a sustainable agriculture and food sector. Agronomy Journal, 100(3), 771-776. https://doi.org/10.2134/agronj2007.0073

González-Calvo, J., González, V. M., \& Lorig, K. (1997). Cultural diversity issues in the development of valid and reliable measures of health status. Arthritis \& Rheumatism, 10(6), 448-456. https://doi.org/10.1002/art.1790100613

Kilpatrick, K. (2014, January 28). In blighted Mantua, a history of poverty, crime and pride. Aljazeera America. Retrieved from http://america.aljazeera.com/articles/2014/1/28/obama-philadelphiapromizezonesmantua.html

Knierim, A., \& Callenius, C. (2018). Transdisciplinary approaches and methods in the context of food and nutrition security. Hidden Hunger: Strategies to Improve Nutrition Quality, 118, 144-151. https://doi.org/10.1159/000484465

Kremer, P., \& Schreuder, Y. (2012). The feasibility of regional food systems in metropolitan areas: An investigation of Philadelphia's foodshed. Journal of Agriculture, Food Systems, and Community Development, 2(2), 171-191. https://doi.org/10.5304/jafscd.2012.022.005

Lahne, J. (2016, June 24). When cooking counts: A pilot quantitative study of the intersection of socioeconomic status and food agency. Scarborough Fare ASFS/AFHVS/CAFS Annual Conference, University of Toronto Scarborough.

Lahne, J., Wolfson, J. A., \& Trubek, A. (2017). Development of the cooking and food provisioning action scale (CAFPAS): A new measurement tool for individual cooking practice. Food Quality and Preference, 62, 96-105. https://doi.org/10.1016/i.foodqual.2017.06.022

Luyt, R. (2012). A framework for mixing methods in quantitative measurement development, validation, and revision: A case study. Journal of Mixed Methods Research, 6(4), 294-316. https://doi.org/10.1177/1558689811427912

Mares, T. M. (2017). Navigating gendered labor and local food: A tale of working mothers in Vermont. Food and Foodways, 25(3), 177-192. https://doi.org/10.1080/07409710.2017.1343064

Marshall, M. N. (1996). Sampling for qualitative research. Family Practice, 13(6), 522-526. https://doi.org/10.1093/fampra/13.6.522

Meenar, M. R. (2017). Using participatory and mixed-methods approaches in GIS to develop a place-based food insecurity and vulnerability index. Environment and Planning A: Economy and Space, 49(5), 1181-1205. https://doi.org/10.1177/0308518X16686352

Meenar, M. R., \& Hoover, B. M. (2012). Community food security via urban agriculture: Understanding people, place, economy, and accessibility from a food justice perspective. Journal of Agriculture, Food Systems, and Community Development, 3(1), 143-160. https://doi.org/10.5304/jafscd.2012.031.013

Morgan, C. B. (2016). Expanding food agency: Exploring the theory and its scale in Philadelphia, PA. UVM Graduate College Dissertations and Theses, No. 661. Retrieved from https://scholarworks.uvm.edu/graddis/661

Mui, Y., Khojasteh, M., Hodgson, K., \& Raja, S. (2018). Rejoining the planning and public health fields: Leveraging comprehensive plans to strengthen food systems in an urban versus rural jurisdiction. Journal of Agriculture, Food Systems, and Community Development, 8(B), 73-93. https://doi.org/10.5304/jafscd.2018.08B.004

Ogden, C. L., Lamb, M. M., Carrol, M. D., \& Flegal, K. M. (2010). Obesity and socioeconomic status in adults: United States 1988-1994 and 2005-2008. NCHS Data Brief, (50), 1-8. Retrieved from https://pubmed.ncbi.nlm.nih.gov/21211165/

Porter, C. M., Woodsum, G. M., \& Hargraves, M. (2018). Introduction—and invitation— to the food dignity special issue. Journal of Agriculture, Food Systems, and Community Development, 8(A) 1-4. https://doi.org/10.5304/jafscd.2018.08A.025

Rose, D. J. (2011). Captive audience? Strategies for acquiring food in two Detroit neighborhoods. Qualitative Health Research, 21(5), 642-651. https://doi.org/10.1177/1049732310387159

Sobal, J., \& Bisogni, C. A. (2009). Constructing food choice decisions. Annals of Behavioral Medicine, 38(1), s37-s46. https://doi.org/10.1007/s12160-009-9124-5

Sutton, D. E. (2014). Secrets from the Greek kitchen: Cooking, skill, and everyday life on an Aegean Island. Oakland: University of California Press.

Trubek, A. B. (2017). Making modern meals: How Americans cook today. Oakland: University of California Press. 
Trubek, A. B., Carabello, M., Morgan, C., \& Lahne, J. (2017). Empowered to cook: The crucial role of 'food agency' in making meals. Appetite, 116, 297-305. https://doi.org/10.1016/j.appet.2017.05.017

U.S. Census Bureau. (n.d.). U.S. Census Burean QuickFacts selected: Vermont. Retrieved September 8, 2017, from https://www.census.gov/quickfacts/VT

Vidgen, H. A., \& Gallegos, D. (2014). Defining food literacy and its components. Appetite, 76, 50-59. https://doi.org/10.1016/j.appet.2014.01.010

Wagner, K. D., Davidson, P. J., Pollini, R. A., Strathdee, S. A., Washburn, R., \& Palinkas, L. A. (2012). Reconciling incongruous qualitative and quantitative findings in mixed methods research: Exemplars from research with drug using populations. International Journal of Drug Policy, 23(1), 54-61. https://doi.org/10.1016/i.drugpo.2011.05.009

Wickson, F., Carew, A. L., \& Russell, A. W. (2006). Transdisciplinary research: Characteristics, quandaries and quality. Futures, 38(9), 1046-1059. https://doi.org/10.1016/i.futures.2006.02.011

Wolfson, J. A., Bleich, S. N., Smith, K. C., \& Frattaroli, S. (2016). What does cooking mean to you?: Perceptions of cooking and factors related to cooking behavior. Appetite, 97, 146-154. https://doi.org/10.1016/j.appet.2015.11.030

Wolfson, J. A., Bostic, S., Lahne, J., Morgan, C., Henley, S. C., Harvey, J., \& Trubek, A. (2017). A comprehensive approach to understanding cooking behavior: Implications for research and practice. British Food Journal, 119(5), 1147-1158. https://doi.org/10.1108/BFJ-09-2016-0438

Zhang, Q., \& Wang, Y. (2004). Socioeconomic inequality of obesity in the United States: Do gender, age, and ethnicity matter? Social Science \& Medicine, 58(6), 1171-1180. https://doi.org/10.1016/S0277-9536(03)00288-0 


\section{Appendix}

The constraint of physical environment included participants' indication of the following, adapted from original narrative form:

1. Kitchen facilities

a. Lack of kitchens in dorms

b. House in disrepair

2. Distance from family who would otherwise cook

3. Distance between work and home (leaving less time for shopping and cooking)

4. Distance from grocery stores

a. No big supermarkets nearby

b. Difficulty of transportation getting to and from markets (traffic; multiple bus changes; long walking distance)

c. Distance from culturally appropriate stores (e.g. Asian markets)

5. Lack of access to gardens

a. Lack of gardening space

b. Violence in the neighborhood

6. Weather (summer too hot for cooking)

Thus, in the qualitative data, people mentioned being constrained by not having kitchens or working electricity in the home; by being far away from people whom they are used to relying on for meals; by the distance they have to travel for work; etc. From these individual specifics, it becomes clear that, as could be expected, people's physical environment affects their agency in a variety of ways, depending on individual circumstance. In Table 1, these appear alongside CAFPAS items as particular experiences (e.g. "Distance from family") and accompanying, broader theme ("Constraint (Income)"). (For in-depth detail on each of these items, see Morgan, 2016.) 